\title{
Erratum to: Mechanisms and constitutive relevance
}

\author{
Mark B. Couch
}

Published online: 21 February 2012

(C) Springer Science+Business Media B.V. 2012

\section{Erratum to: Synthese (2011) 183:375-388 DOI 10.1007/s11229-011-9882-z}

\section{Incorrect text in footnote 5: the mistakes are underlined}

Notice the Craver describes constitutive relevance as "a relationship between a component in the mechanism and the behavior of a mechanism and the behavior of a mechanism as a whole" (2007, p. 146, n 26). Understood this way, it is _ relationship between a component and the mechanism's behavior. But when it comes to the account he explains how to ascertain if a component is relevant to the mechanism's behavior (not the relation), which is something different.

\section{The correct text as it should read}

Notice that Craver describes constitutive relevance as "a relationship between a component in the mechanism and the behavior of a mechanism as a whole" (2007, p. 146, n26). Understood this way, it is a relationship between a component and the mechanism's behavior. But when it comes to the account he explains how to ascertain if a component is relevant to the mechanism's behavior (not the relation), which is something different.

The online version of the original article can be found under doi:10.1007/s11229-011-9882-z.

M. B. Couch $(\varangle)$

Department of Philosophy, Seton Hall University, 400 South Orange Ave., South Orange, NJ 07079, USA

e-mail: mark.couch@shu.edu 